\title{
Perceived sensory dimensions: Key aesthetic qualities for health-promoting urban green spaces
}

Jonathan Stoltz*, Patrik Grahn

Department of People and Society, Swedish University of Agricultural Sciences, Alnarp, Sweden

*Author for correspondence: Email: jonathan.stoltz@slu.se

Received date: May 04, 2021 Accepted date: October 22, 2021

Copyright: $\odot 2021$ Stoltz J, et al. This is an open-access article distributed under the terms of the Creative Commons Attribution License, which permits unrestricted use, distribution, and reproduction in any medium, provided the original author and source are credited.
Citation: Stoltz J, Grahn P. Perceived sensory dimensions: Key aesthetic qualities for health-promoting urban green spaces. J Biomed Res 2021;2(1):22-29.
The importance of urban green areas to support people's health and wellbeing has been confirmed by many studies [1]. In addition to regulating functions regarding water, air, and climate, urban green spaces can also contribute through psychologically driven pathways to, e.g., aid restoration from stress and attention fatigue and to promote physical activity (ibid.). Close-by access and visit times have been identified as crucial factors to support such pathways [2]. Other important factors are size [3] and the internal qualities of the green area, aspects that are often closely related. At the same time, many studies claim that there is a lack of evidence-based tools that can guide work regarding perceived qualities of urban green areas [4-7]. Our paper [8] summarizes findings made over several studies during the past 35 years regarding the most important perceived qualities of urban green spaces, qualities that people wish to experience when visiting. It aims to present these findings as a coherent theoretical model and suggests eight fundamental principles, eight perceived sensory dimensions, to consider in the planning and design of urban green areas to support people's common needs.

Among previous studies on connections between perceived green spaces qualities and people's health and wellbeing some studies have focused on experiences of diversity and species richness [9-11]. Other studies have focused on various social activities and include such things as restaurants, kiosks, toilets, seating, lighted roads, etc. (e.g., $[12,13])$. There are also many studies on the importance of a perceived naturalness in the green area (e.g., [14,15]). To offer opportunities for restoration researchers have suggested the importance of providing a sense of shelter [16] as well as of extent, of entering a coherent "different world" $[17,18]$. In a similar regard, experiences of tranquility in urban green spaces have also been studied (e.g., [19]). Furthermore, the need for large open areas that make possible various physical activities has been mentioned, as well as the importance of cultural influence in green areas, e.g., through decorations with flowers, fountains, etc. We believe all these aspects to be represented through the eight distinct perceived sensory dimensions proposed in our model, interrelated as illustrated in Figure 1.

The model places these eight qualities along four axes. Each axis has two opposing qualities that need to be balanced against each other as they are often associated with opposite attributes. Adjacent qualities in the model on the other hand are seen as synergistic and often support each other in an environment. We propose that support for between two and four such closely related qualities can contribute to places with high aesthetic function and low conflict between different qualities. Not all qualities need to be supported within one and the same green area, but we suggest that all eight ideally should be represented in the outdoor environment within approximately 300 meters of the dwelling.

A Natural quality describes places where the greenery appears to be natural and spontaneously grown-up, offering the experience of a relative absence of human influence. It is often associated with larger green areas and mature vegetation (Figure 2). Impressions of self-sown plants and undisturbed development over time characterize the place. A Serene quality is found in places that are perceived as peaceful, tranquil and with few people (Figure 3). Both naturalness and serenity are often linked to large areas and the two qualities seem to support each other. They thus appear as neighbors in the model. 


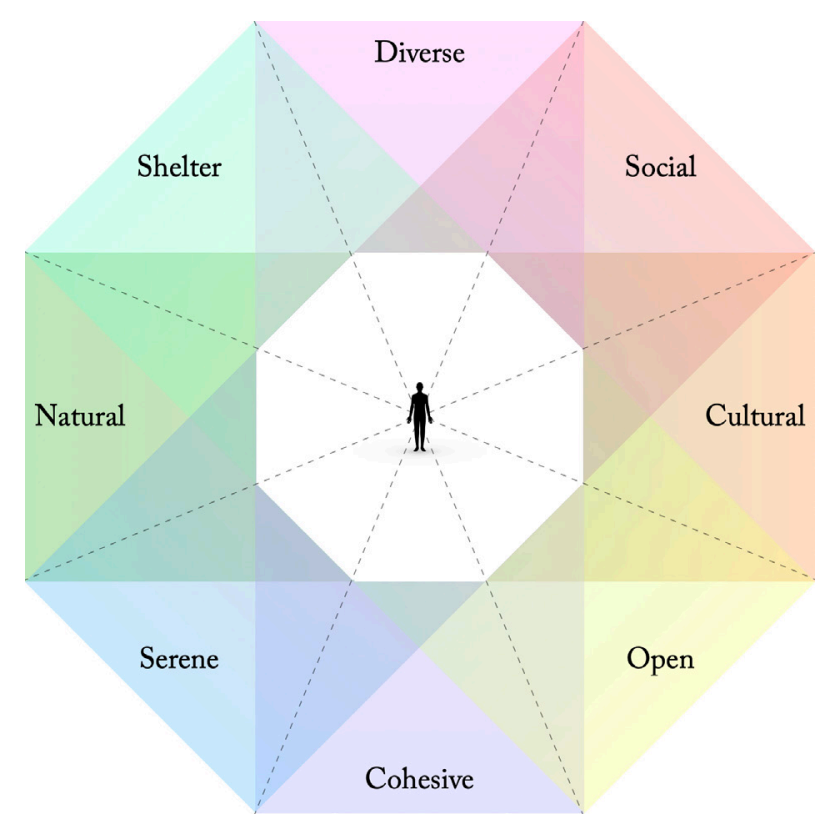

Figure 1: Eight perceived sensory dimensions supporting complementary needs. All qualities do not need to be supported within one and the same green area, but all should ideally be afforded within $300 \mathrm{~m}$ from the home.

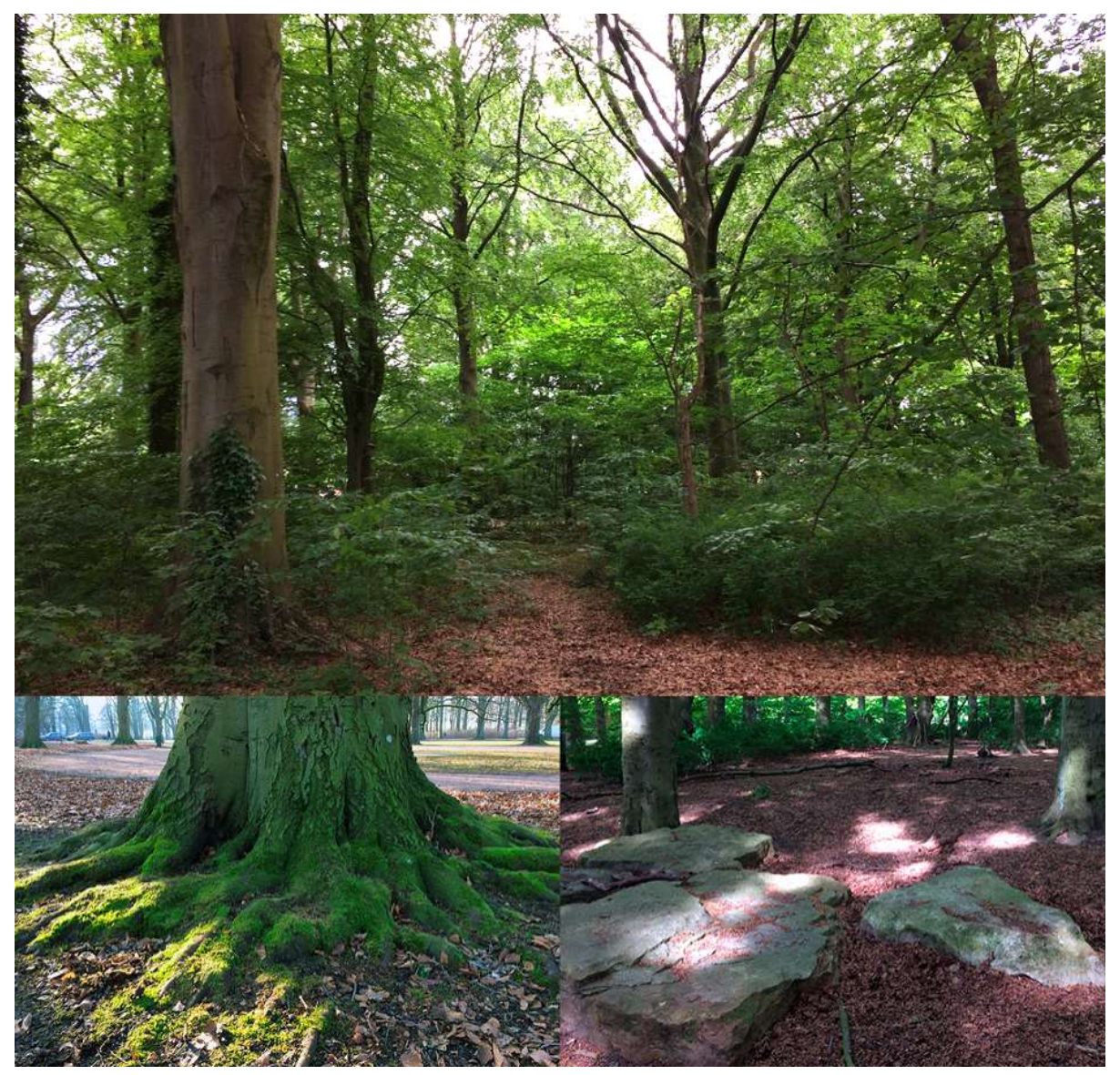

Figure 2: A Natural quality is often associated with larger green areas and mature vegetation. Veteran trees, moss and naturally shaped stones are some examples of structural elements that can support such a quality in an urban context. 


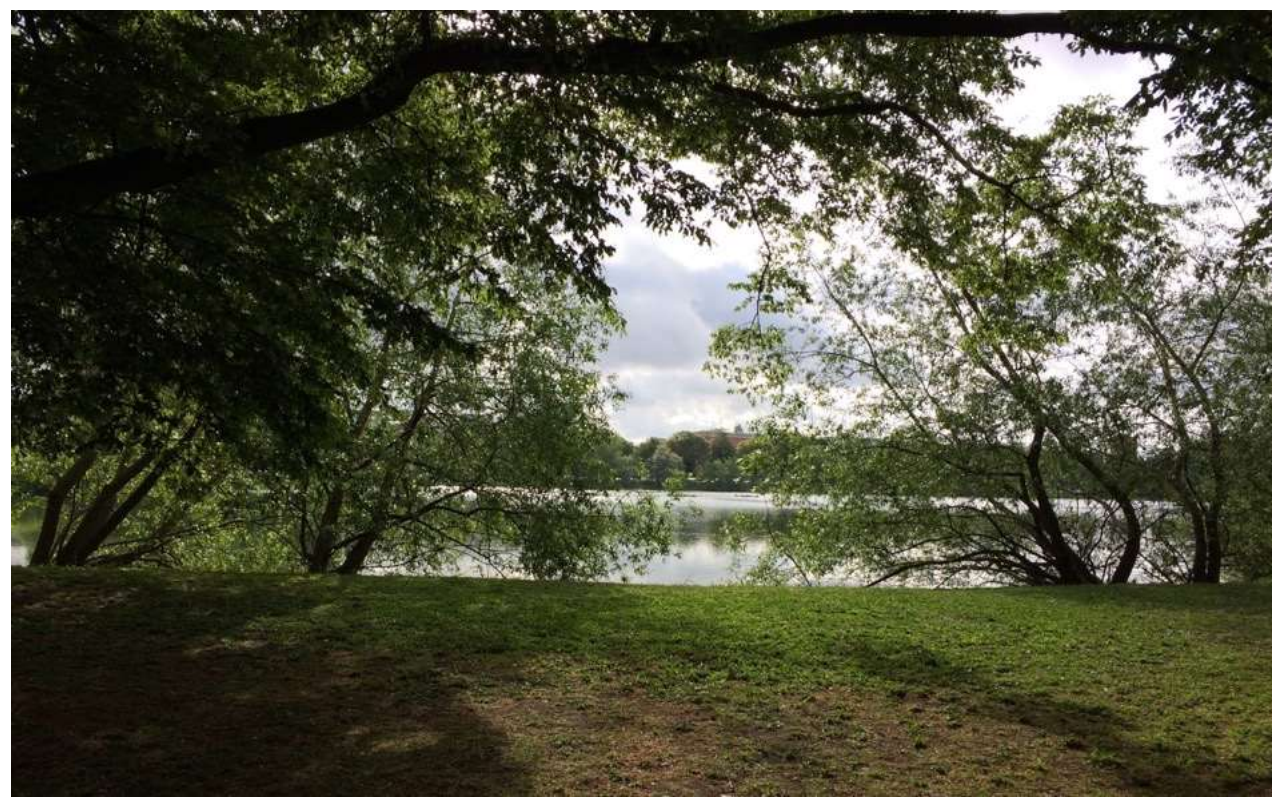

Figure 3: A Serene quality is made possible in undisturbed places, where the city's noise is reduced and characterized by a relative absence of other people. It is often associated with perceived naturalness, as well as with larger, cohesive areas.

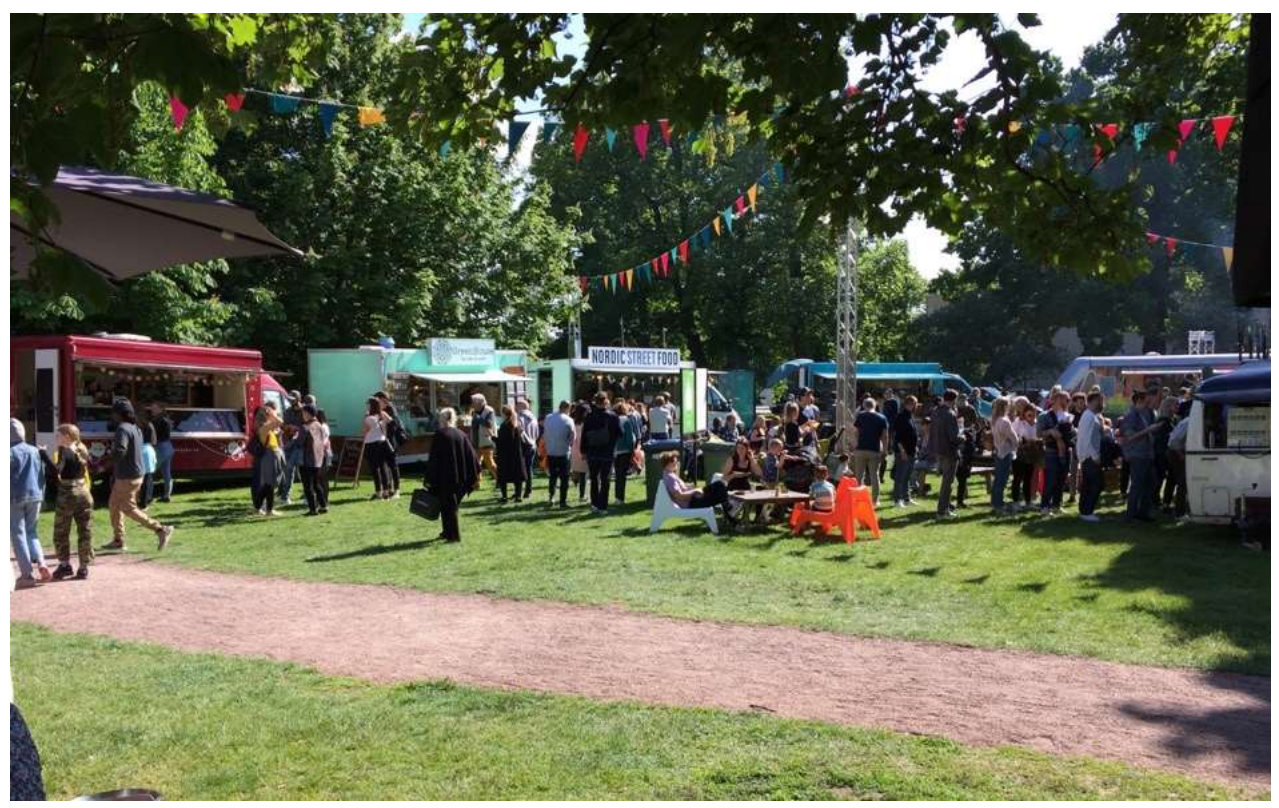

Figure 4: A Social quality is associated with places where people gather and meet. It can be supported in relatively small green areas and be reinforced through a densified design and planning of the site.

Opposed to serenity in the model is a Social quality, associated with places with lots of people, life, and movement. This quality is often strong around social meeting places such as larger playgrounds, cafés, restaurants, or at various cultural events (Figure 4). It might thus in many ways be regarded as an essentially urban quality. It commonly occurs together with a Cultural quality, which describes places with a significant and evident degree of human impact (Figure 5). It can, for example, be strengthened through various building constructions, flower beds, fountains, art installations, sculptures, etc. As such, it stands in clear contrast to the opposing Natural quality. Both a Social and a Cultural quality seem easy to support also in relatively small green areas.

Open is a quality attributed to large, open spaces for activity or places with long, unbroken sight lines. In an urban context it is often associated with large lawns (Figure 6) but can also be experienced in natural areas such as meadows or beaches, with lots of room for movement and distant views. Such open areas often also support a Cohesive quality, which describes a green area's potential to evoke an experience of a cohesive, extended whole, which can surround the visitor and invite discoveries in many directions (Figure 7). This preferably without the boundaries of the area being immediately 


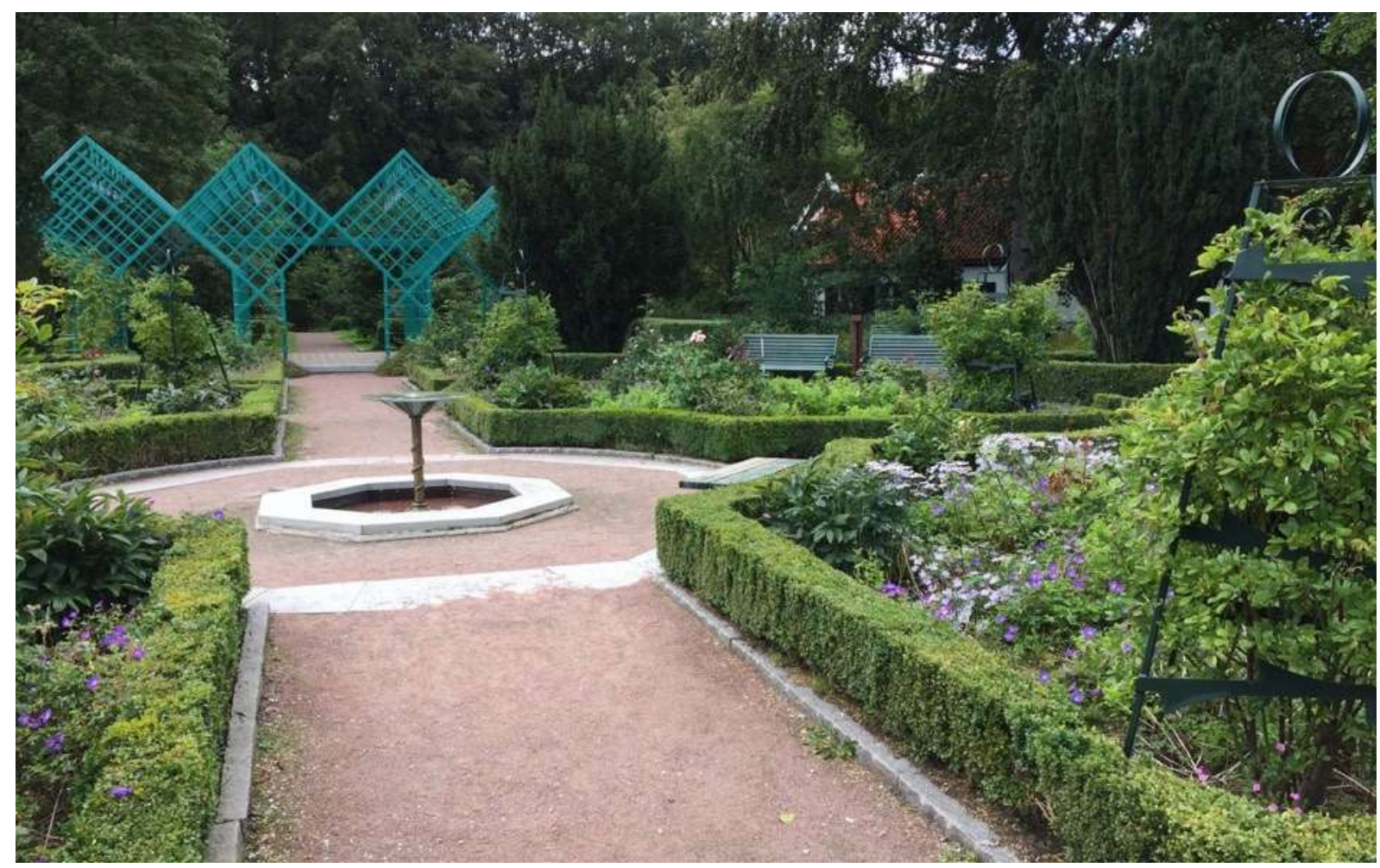

Figure 5: A Cultural quality increases with the significance and distinction of human impact at the site. Art installations, statues, fountains, clearly managed plantations, flower beds, etc. can all contribute to this quality.

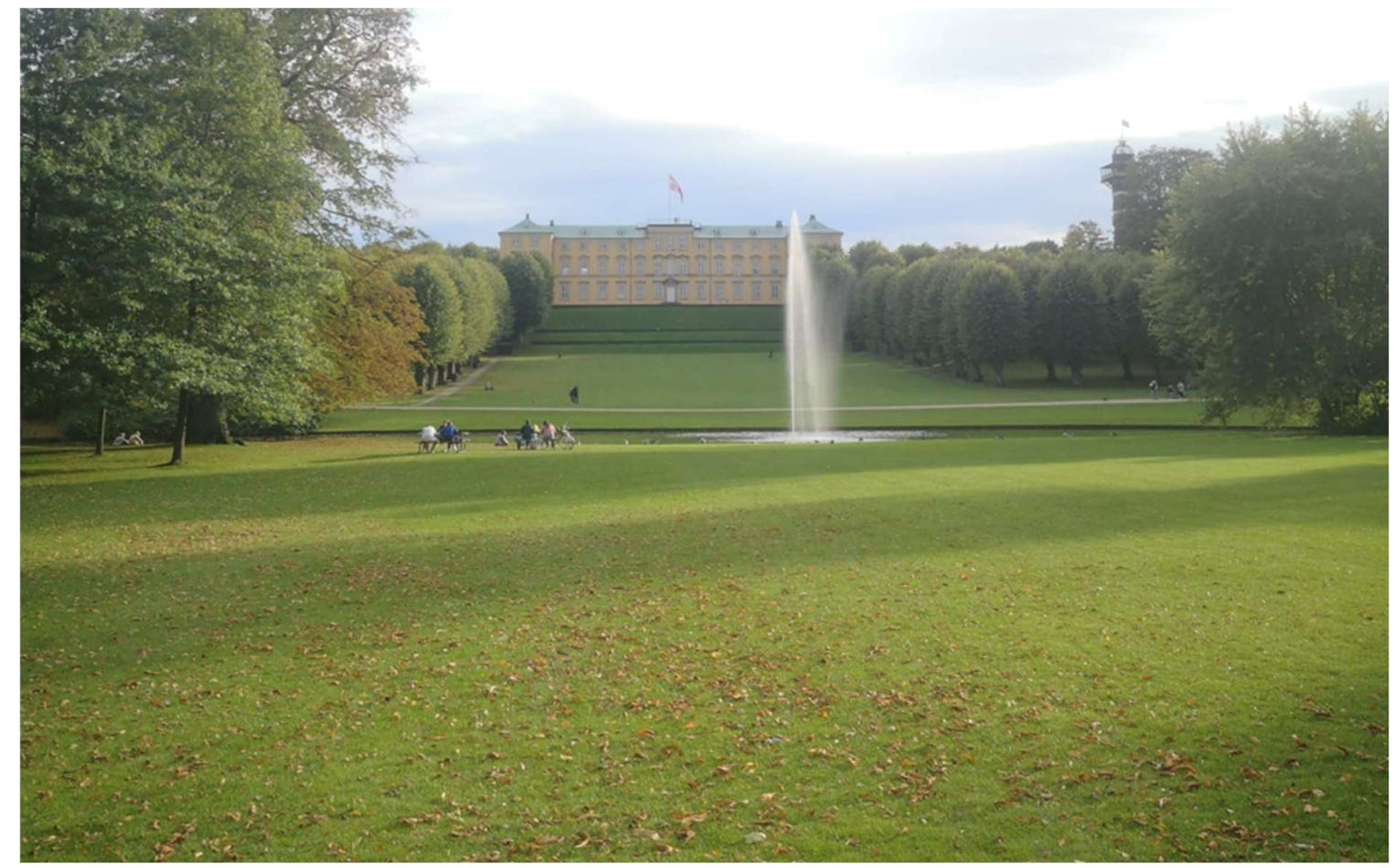

Figure 6: An Open quality offers the visitor long, unbroken sightlines and generous areas for various activities. In an urban context it is often associated with big lawns. 


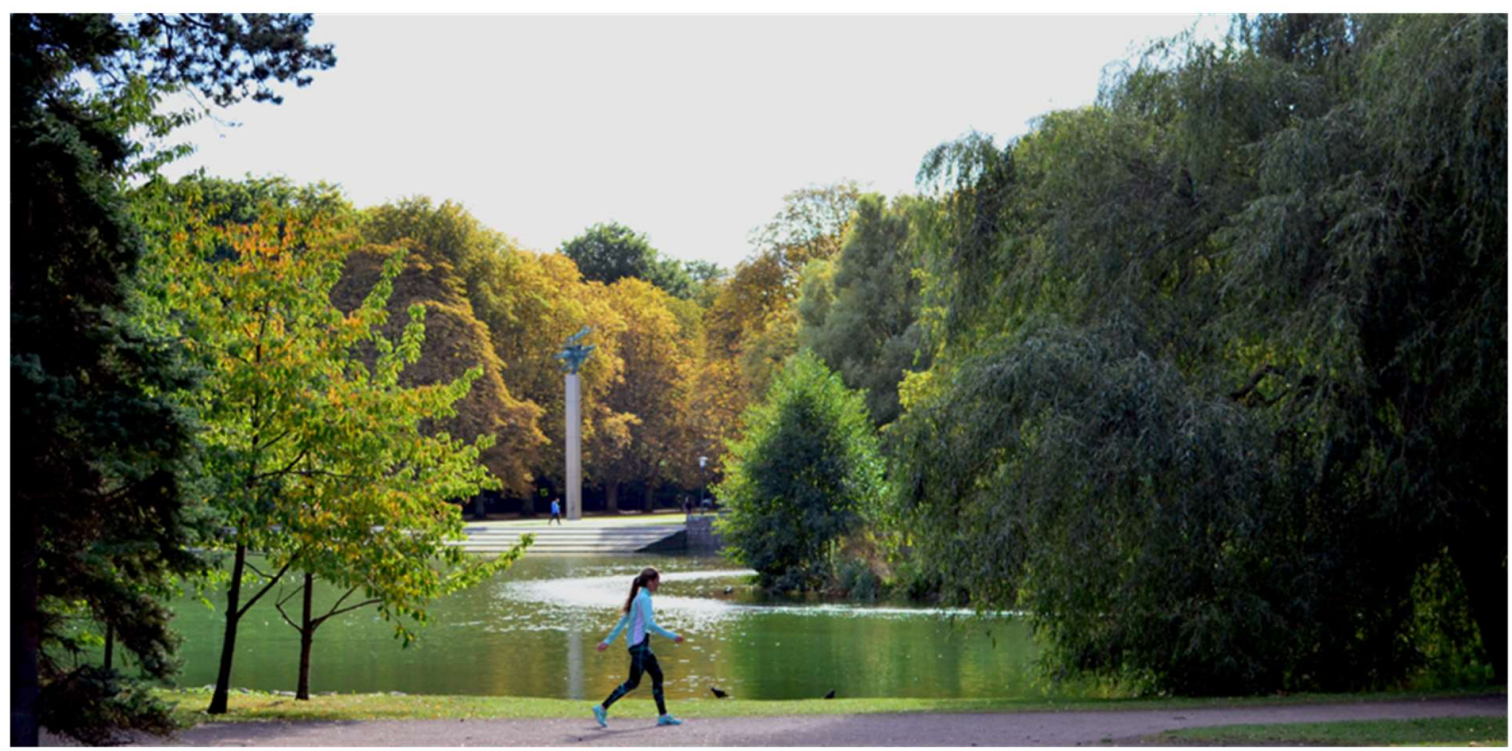

Figure 7: A Cohesive quality describes the potential of a green area to create an experience of a coherent whole surrounding the visitor. It depends on both the size of the green area and its structure. The larger the area, the better can be a simple rule of thumb. It is also important however that the place retains a spatially unified and structurally coherent character.

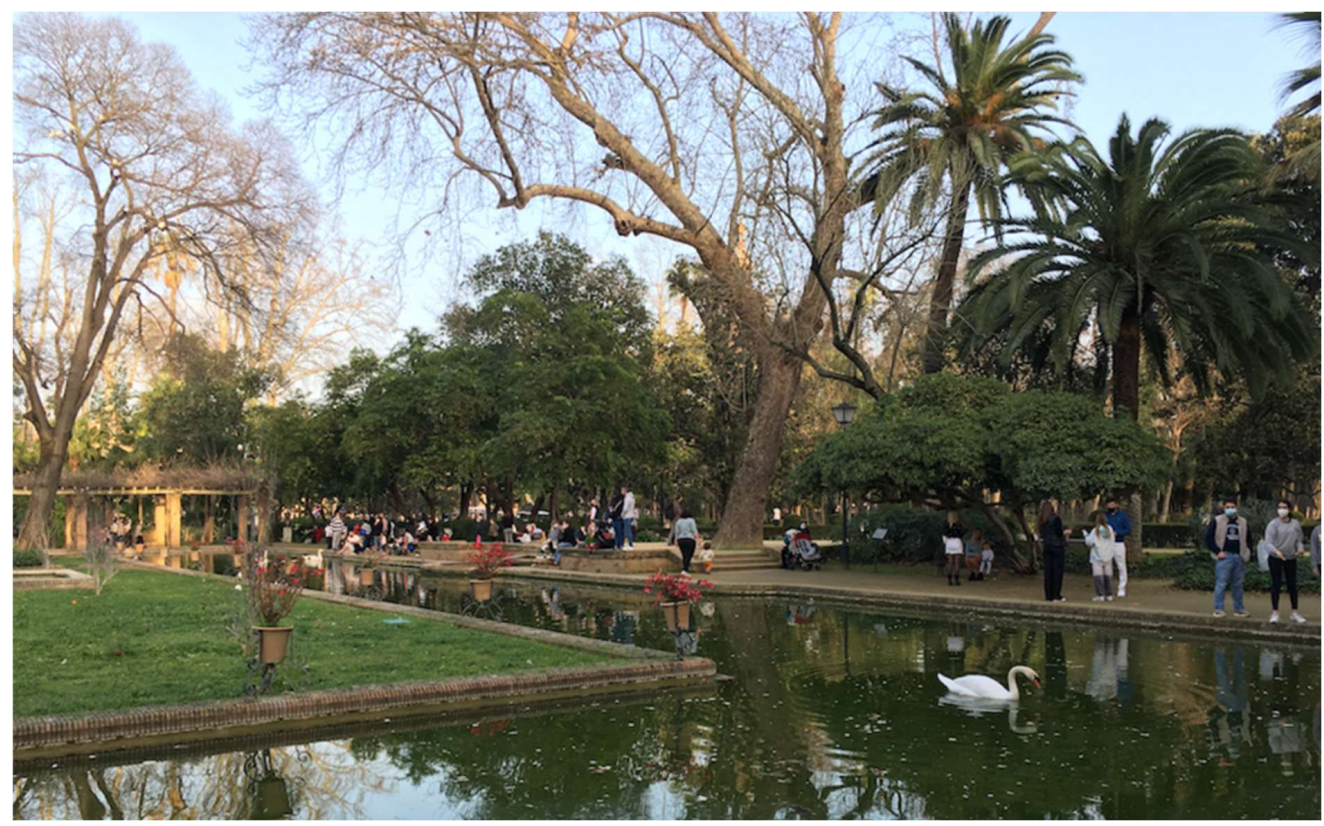

Figure 8: Experiences of Diversity can be supported through structural variation and the presence of different elements, such as stone, water, a varied vegetation and conditions supporting a rich wildlife.

visible. It depends on several spatial fac-tors, such as, e.g., how roads are drawn through the area, its size, buildings that are part of or enclose the area, and shielding from the surrounding urban landscape. It can also be about structural elements, such as, e.g., a unified and coherent vegetational structure, that connects the area and creates the experience of an extended "world in itself". As such, we believe this factor to be strongly related to the extent quality suggested by Kaplan [17] as an essential perceived quality of restorative environments, including aspects of environmental coherence as well as scope [18].
A Diverse quality on the other hand, arises when variations in spatial structure, materials, textures, and species offer a diversity of sensory impressions. It can, for example, be supported through various structural elements, such as stone and water, a varied vegetation in terms of structure and species composition, as well as habitat conditions supporting a varied wildlife (Figure 8). It often occurs together with a Sheltered quality, where the visitor is offered a secluded safe place while maintaining contact with the outside world (Figure 9). This quality usually emerges in smaller, somewhat enclosed spaces, preferably in the protection of vegetation. Such 


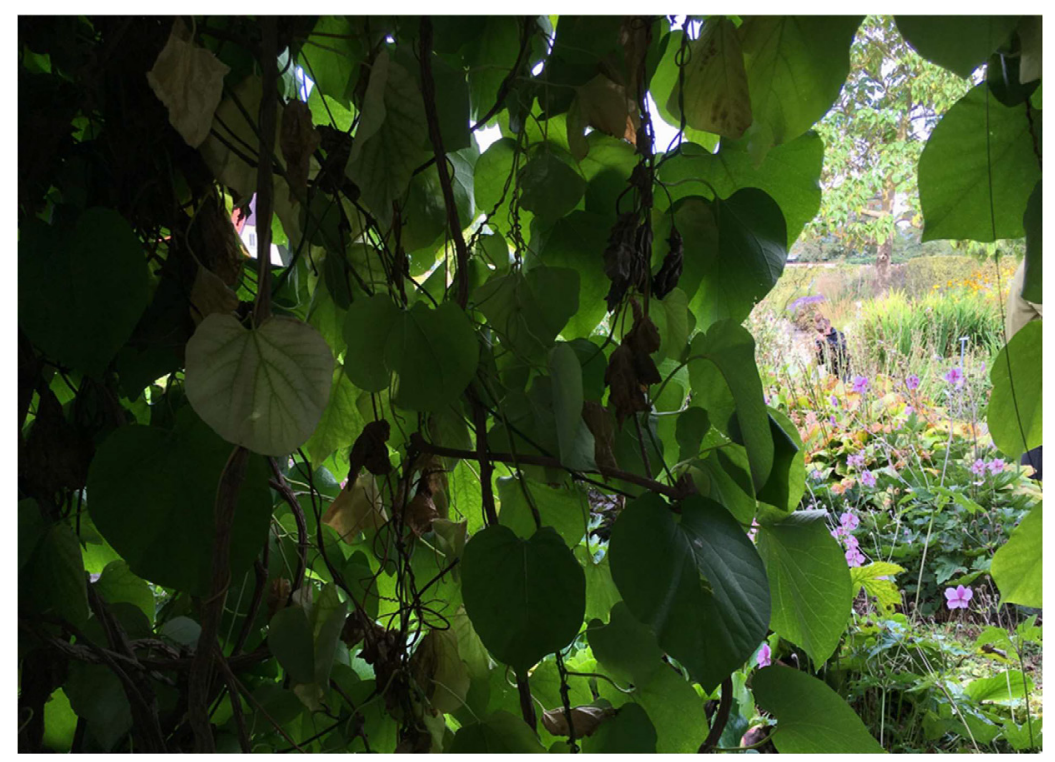

Figure 9: "To see without being seen" is a need expressed by many exhausted and stressed people. A Sheltered quality arises when the visitor is offered a protected and safe place while outlooks maintain contact with the outside world.

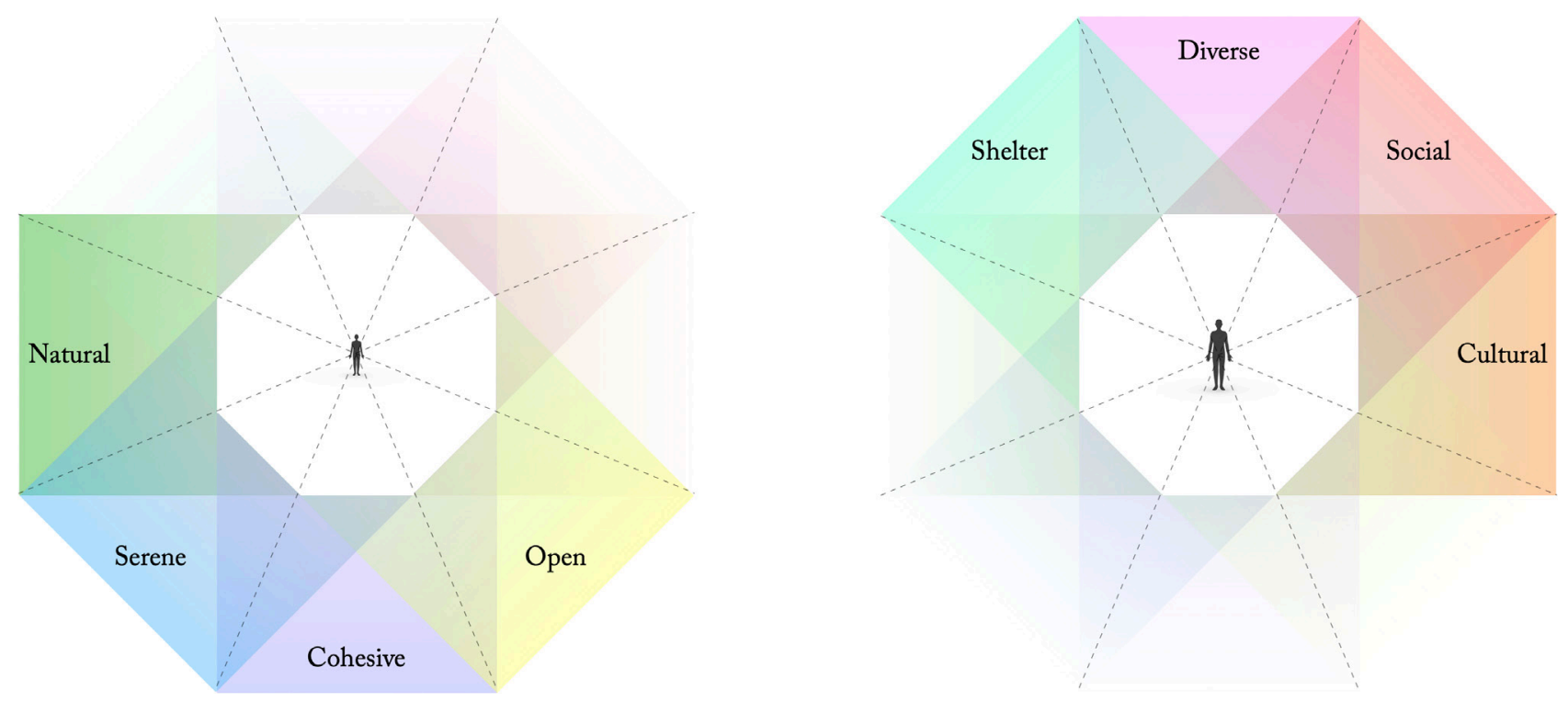

Figure 10: A distinction is made between perceived qualities often associated with larger green areas (left) and those usually requiring less space to be supported (right).

sheltered sites are often associated with experiences of naturalness and diversity.

A distinction is made in the model between the qualities that are most often associated with larger green areas - a Natural, Serene, Cohesive, and Open quality respectively - and those that often occur also in smaller areas, the opposing Cultural, Social, Diverse, and Sheltered qualities (Figure 10).

Another distinction (Figure 11) is made between qualities particularly associated with restoration from stress and exhaustion (i.e., Sheltered, Natural, Serene and Cohesive) and those often preferred only when stress and fatigue reach lower levels (Diverse, Social, Cultural, and Open).

It is sometimes argued that green spaces of high quality are possible to achieve within smaller areas. From a perceived qualities perspective however, as we have seen, this might be true for certain qualities but not for others. This could be important to keep in mind with regards to densification processes, where green areas often are considered as potential sites for new buildings. Restorative greenspace functions might then be particularly sensitive to densification processes where urban green areas are made smaller to give room for new buildings. 


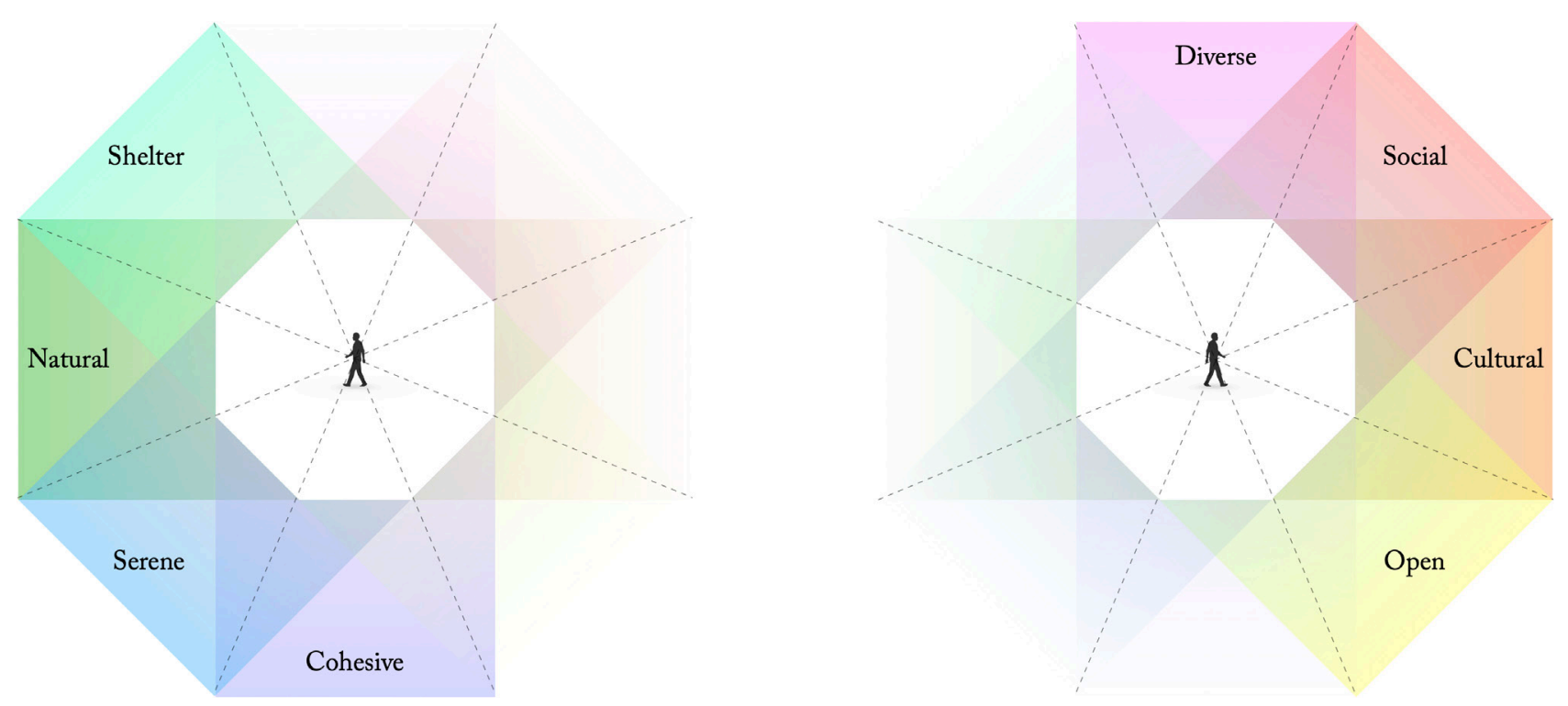

Figure 11: Research shows that people in need of stress recovery to a greater extent seek out environments perceived as Natural, Sheltered, Serene, and Cohesive (left). As the need for recovery decreases, Cultural, Open, Diverse and Social environments often become more important (right).

Studies have been conducted to investigate how exposure to the eight described perceived sensory dimensions affects outdoor activities and wellbeing. Two major public health surveys $[20,21]$ show that if people live near green areas that offer more of these qualities, their physical activity increases. In addition, the study by Björk et al. [20] showed that the risk of obesity decreased, while the study by de Jong et al. showed that the inhabitants estimated their health to be better. The studies also showed a clear link between living near green areas with many qualities and preference of the residential area. A larger population study showed that exposure to Serene, Natural and Sheltered was associated with lower stress values [22]. Studies in nature-based therapy gardens also show these three qualities to be the most important in early stages of rehabilitation from stress-related mental illness [23]. An extensive longitudinal epidemiological study showed that moving to an area characterized as rich in the Serene quality reduced the risk of stressrelated mental illness [24]. Overall, results indicate that health promoting urban design and planning should consider the need for variation in terms of the perceived sensory dimensions offered to people in order to support different, and often complimentary, needs in the population.

\section{References}

1. Nilsson $K$, Bentsen $P$, Grahn $P$, Mygind L. What is the scientific evidence with regard to the effects of forests, trees on Human Health and well-being? Santé Publique. 2019(HS1):219-40.

2. Grahn P, Stigsdotter UA. Landscape planning and stress. Urban Forestry \& Urban Greening. 2003 Jan 1;2(1):1-8.

3. Wood L, Hooper P, Foster S, Bull F. Public green spaces and positive mental health-investigating the relationship between access, quantity and types of Parks and Mental Wellbeing. Health \& Place. 2017 Nov 1;48:63-71.

4. Nigussie S, Liu L, Yeshitela K. Indicator development for assessing recreational ecosystem service capacity of urban green spaces- $A$ participatory approach. Ecological Indicators. 2021 Feb 1;121:107026.
5. Knobel P, Dadvand P, Maneja-Zaragoza R. A systematic review of multi-dimensional quality assessment tools for Urban Green Spaces. Health \& Place. 2019 Sep 1;59:102198.

6. Labib SM, Lindley S, Huck JJ. Spatial dimensions of the influence of urban green-blue spaces on human health: A systematic review. Environmental Research. 2020 Jan 1;180:108869.

7. Ekkel ED, de Vries S. Nearby green space and human health: Evaluating accessibility metrics. Landscape and urban Planning. 2017 Jan 1;157:214-20.

8. Stoltz J, Grahn P. Perceived sensory dimensions: An evidencebased approach to greenspace aesthetics. Urban Forestry \& Urban Greening. 2021 Apr 1;59:126989.

9. Fuller RA, Irvine KN, Devine-Wright P, Warren PH, Gaston KJ. Psychological benefits of greenspace increase with Biodiversity. Biology Letters. 2007 Aug 22;3(4):390-4.

10. Dallimer M, Irvine KN, Skinner AM, Davies ZG, Rouquette JR, et al. Biodiversity and the feel-good factor: understanding associations between self-reported human well-being and species richness. BioScience. 2012 Jan 1;62(1):47-55.

11. Gyllin M, Grahn P. Semantic assessments of experienced biodiversity from photographs and on-site observations - a comparison. Environment and Natural Resources Research. 2015;5:46-62.

12. Giles-Corti B, Broomhall MH, Knuiman M, Collins C, Douglas $K$, et al. Increasing walking: how important is distance to, attractiveness, and size of public open space? American Journal of Preventive Medicine. 2005 Feb 1;28(2):169-76.

13. Hillsdon M, Panter J, Foster C, Jones A. The relationship between access and quality of urban green space with population physical activity. Public Health. 2006 Dec 1;120(12):1127-32.

14. Ode Å, Fry G, Tveit MS, Messager P, Miller D. Indicators of perceived naturalness as drivers of landscape preference. Journal of Environmental Management. 2009 Jan 1;90(1):375-83.

15. Carrus G, Lafortezza R, Colangelo G, Dentamaro I, Scopelliti M, et al. Relations between naturalness and perceived restorativeness of 
different Urban Green Spaces. Psyecology. 2013 Jan 1;4(3):227-44.

16. Sonntag-Öström E, Stenlund T, Nordin M, Lundell Y, Ahlgren C, et al. "Nature's effect on my mind"-Patients' qualitative experiences of a forest-based rehabilitation programme. Urban Forestry \& Urban Greening. 2015 Jan 1;14(3):607-14.

17. Kaplan S. The restorative benefits of nature: Toward an integrative framework. Journal of Environmental Psychology. 1995 Sep 1;15(3):169-82.

18. Pasini M, Berto R, Brondino M, Hall R, Ortner C. How to measure the restorative quality of environments: The PRS- 11 . Procedia-Social and Behavioral Sciences. 2014 Dec 23;159:293-7.

19. Marafa LM, Tsang F, Watts G, Yuan XM. Perceived tranquility in green urban open spaces. World Leisure Journal. 2018 Jul 3;60(3):221-34.

20. Björk J, Albin M, Grahn P, Jacobsson H, Ardö J, et al. Recreational values of the natural environment in relation to neighbourhood satisfaction, physical activity, obesity and wellbeing. Journal of Epidemiology \& Community Health. 2008 Apr 1;62(4):e2.
21. De Jong K, Albin M, Skärbäck E, Grahn P, Björk J. Perceived green qualities were associated with neighborhood satisfaction, physical activity, and general health: Results from a cross-sectional study in suburban and rural Scania, southern Sweden. Health \& Place. 2012 Nov 1;18(6):1374-80.

22. Grahn P, Stigsdotter UK. The relation between perceived sensory dimensions of urban green space and stress restoration. Landscape and Urban planning. 2010 Mar 15;94(3-4):264-75.

23. Pálsdóttir AM, Stigsdotter UK, Persson D, Thorpert $P$, Grahn P. The qualities of natural environments that support the rehabilitation process of individuals with stress-related mental disorder in nature-based rehabilitation. Urban Forestry \& Urban Greening. 2018;29:312-321.

24. van den Bosch MA, Östergren PO, Grahn P, Skärbäck E, Währborg $P$. Moving to serene nature may prevent poor mental healthresults from a Swedish longitudinal cohort study. International Journal of Environmental Research and Public Health. 2015 Jul;12(7):7974-89. 